\title{
Investigation of the alumina properties with adsorbed polyvinyl alcohol
}

\author{
Małgorzata Wiśniewska • Stanisław Chibowski • \\ Teresa Urban · Dariusz Sternik
}

Received: 22 January 2010/Accepted: 6 September 2010/Published online: 21 September 2010

(C) The Author(s) 2010. This article is published with open access at Springerlink.com

\begin{abstract}
The influence of solution $\mathrm{pH}$ on the structure of polyvinyl alcohol adsorption layer on the alumina surface was investigated. The spectrophotometry, viscosimetry, thermogravimetry, potentiometric titration and microelectrophoresis were applied in experiments. These methods enable determination of the following parameters: adsorbed amount of PVA, stability of suspension without and with polymer, thickness of its adsorption layers, changes in thermal characteristics of $\mathrm{Al}_{2} \mathrm{O}_{3}$ surface with the adsorbed polymer, surface charge density and zeta potential of solid particles in the presence and absence of PVA, respectively. All measurements were carried out in the $\mathrm{pH}$ range 3-9. The obtained results indicate that $\mathrm{pH}$ has a great influence on the conformation of PVA chains adsorbed on the alumina surface. It is due to incomplete hydrolysis of acetate groups of polyvinyl alcohol macromolecules (degree of hydrolysis $97.5 \%$ ), which dissociate with the increasing $\mathrm{pH}$. Moreover, the polymer adsorption on the alumina surface causes changes in the course of thermogravimetric curves. The effect of weight loss for $\mathrm{Al}_{2} \mathrm{O}_{3}$-PVA systems is smaller than that of $\mathrm{Al}_{2} \mathrm{O}_{3}$ without polymer. It is due to elimination of water molecules from the solid surface by adsorbed polymer.
\end{abstract}

M. Wiśniewska $(\bowtie) \cdot S$. Chibowski · T. Urban

Department of Radiochemistry and Colloids Chemistry, Faculty of Chemistry, Maria Curie Sklodowska University, M. Curie Sklodowska Sq. 3, 20-031 Lublin, Poland

e-mail: wisniewska@hektor.umcs.lublin.pl

D. Sternik

Department of Physicochemistry of Solid Surface, Faculty of Chemistry, Maria Curie Sklodowska University, M. Curie Sklodowska Sq. 3, 20-031 Lublin, Poland
Keywords Polyvinyl alcohol - Alumina $\cdot$ Polymer conformation - Thermogravimetry $\cdot \mathrm{pH}$ influence

\section{Introduction}

Adsorption of macromolecular substances on the solids surface is important for controlling of many technological and ecological processes. The interfacial properties of metal oxide-polymer solution systems are substantial to mineral flotation, dispersion-flocculation of cosmetics, paints, pharmaceuticals, foods, oil recovery and regulation of plough-lands erosion.

The structure of polymer adsorption layer is conditioned by specified conformation of adsorbed polymer chains. This conformation results from type and strength of forces between the solid active sites and the polymer segments. The energy of polymer-surface interactions is the driving force of adsorption. This process is counteracted by entropy effect, which opposes adsorption. Thus, the conformation of polymer chains is a result of these two competitive effects. Nevertheless, the adsorption process depends on many other parameters associated with nature of solid surface, polymer type and solution conditions [1-5]. The most important factors influencing adsorption process of macromolecules on the metal oxide surface are: (a) solid properties - surface charge density, its purity, size and shape of adsorbent particles; (b) polymer characteristics-its weight average molecular weight, concentration, polydispersity and degree of dissociation of polymer functional groups; (c) solution conditions- $\mathrm{pH}$, ionic strength and temperature.

Conformation of polymer chains (both adsorbed and unadsorbed in the bulk solution) determine the stability of the solid suspension [6-11]. Polymer chains adsorbed on 
the solid particles surface may be responsible for steric stabilization (low molecular weights, high concentrations) or bridging flocculation (high molecular weights, low concentrations) of the suspension. The depletion forces may occur in the case of high concentrations of unadsorbed macromolecules in the solution (depletion stabilization and flocculation processes). To determine the optimal conditions for obtaining a stable or unstable system, it is necessary to investigate and understand the adsorption mechanism of polymer on the solid surface.

Taking the above into consideration, the purpose of this paper was determination of the solution $\mathrm{pH}$ influence on conformation of polyvinyl alcohol (PVA) on the alumina surface. Despite the fact, that PVA is classified as a nonionic polymer, its macromolecules contain acetate groups, which remain after incomplete hydrolysis process of polyvinyl acetate. These groups undergo dissociation, contrary to hydroxyl ones, so solution $\mathrm{pH}$ has great influence on adsorption and stabilization properties of the $\mathrm{Al}_{2} \mathrm{O}_{3}$-PVA systems.

Both polyvinyl alcohol and alumina find a wide practical application. PVA has great usage in food industry as a binding and coating agent to retain the overall satisfactory taste, texture and quality of the food. Moreover, it is a very popular component of cements, varnishes, as a stabilizer of paints, pharmaceutical thickeners as well as in the production of protective gloves, surgical threads, foils, plates and pipes resistant to benzene and oils.

The alumina was chosen for the studies because this popular adsorbent has a well defined solid-liquid interface [12]. Moreover, the alumina is often applied in water purification in removal of dissolved hazardous organic contaminants and is the catalyst of ozonation and wet air oxidation processes. Its polishing properties are also used for CD/DVD burnishing and in toothpaste. On the other hand, its high durability, strength and hardness find application in production of fire-proof materials, strong glasses and precious stones.

\section{Experimental}

The samples of crystalline $\gamma-\mathrm{Al}_{2} \mathrm{O}_{3}$ (Merck) were used in the experiments. The aluminium oxide was washed with doubly distilled water to achieve the supernatant conductivity less than $2 \mu \mathrm{S} \mathrm{cm}^{-1}$. The alumina was characterized by the following parameters: the BET specific surface area $155 \mathrm{~m}^{2} \mathrm{~g}^{-1}$, the average pore diameter $6.1 \mathrm{~nm}$ (lowtemperature adsorption-desorption of nitrogen, automatic adsorption analyzer ASAP 2405, Micromeritics Instruments) and the mean grain size $496 \mathrm{~nm}$ (electrokinetic measurements, Zetasizer 3000 laser zetameter, Malvern Instruments).
The samples of polyvinyl alcohol-PVA (Fluka) with the following weight average molecular weights 22,000 and 72,000 and the degree of hydrolysis $97.5 \%$ was used in the study. Polymer solutions were filtered through the cellulose membranes (Millipore) to eliminate both inorganic contamination and lower and higher polymer fractions. The PVA 22,000 solution was filtered through membranes with NMWL (Nominal Molecular Weight Limit) equal 10,000 and 30,000, whereas the PVA 72,000-30,000 and 100,000. In the case of PVA 72,000 its average molecular weight after the filtration process was determined using viscosity methods [13]. This molecular weight was equal to 38,000 .

All measurements were carried out at $25{ }^{\circ} \mathrm{C}$ in the 3-9 $\mathrm{pH}$ range and the $\mathrm{NaCl}$ solution $\left(1 \times 10^{-2} \mathrm{~mol} \mathrm{dm}^{-3}\right)$ was used as the supporting electrolyte.

The adsorption measurements were taken with the static method in the 10-200 ppm polymer concentration range and with $0.04 \mathrm{~g}$ of $\mathrm{Al}_{2} \mathrm{O}_{3}$. The prepared suspensions were shaken in a water bath (OLS 2000, Grant) for $24 \mathrm{~h}$. The $\mathrm{pH}$ of solutions was set and checked in the time of experiment by the use of $\mathrm{pH}$-meter $\phi 360$ (Beckman) as well as $\mathrm{HCl}$ and $\mathrm{NaOH}$ solutions. Next, the suspensions were centrifuged and $5 \mathrm{~mL}$ of the clear polymer solutions were collected to the further analysis. The amount of the polymer adsorbed was determined from the difference between the PVA concentration in the solution before and after the adsorption process. The concentration of polymer was determined from the reaction of polyvinyl alcohol with boric acid $\left(\mathrm{H}_{3} \mathrm{BO}_{3}\right)$ and iodide solution $\left(\mathrm{I}_{2}\right)$ [14-16]. The obtained complex coloured the solution green. Its absorbance was measured with the UV-VIS Specord M42 spectrophotometer (Carl Zeiss Jena) at the wavelength $682 \mathrm{~nm}$ after $15 \mathrm{~min}$ from the start of the reaction.

The thickness of the polymer adsorption layers $(\delta)$ was determined from the viscosity measurements [17] using a CVO 50 rheometer (Bohlin Instruments). For this purpose the following dependencies were used:

$\delta=r\left[\left(\frac{\phi_{\mathrm{p}}}{\phi_{\mathrm{o}}}\right)^{1 / 3}-1\right]$

where $r$ radius of the solid particle/nm, $\phi_{\mathrm{o}}$ volume fraction of the solid without polymer, $\phi_{\mathrm{p}}$ volume fraction of the solid with polymer.

$\frac{\eta}{\eta_{\mathrm{o}}}=1+k \phi_{\mathrm{o}}$

where $\eta$ viscosity of the suspension/Pa s, $\eta_{\mathrm{o}}$ viscosity of the liquid phase/Pa s, $k$ Einstein coefficient (for the alumina $k=8.73$ ).

The viscosity measurements in the presence of PVA were made with the volume fraction of $\mathrm{Al}_{2} \mathrm{O}_{3}$ equal to $12.6 \times 10^{-3}$. 
The probes for thermogravimetric measurements were prepared by adding $0.6 \mathrm{~g}$ of $\mathrm{Al}_{2} \mathrm{O}_{3}$ to $150 \mathrm{~mL}$ of $\mathrm{NaCl}$ or $\mathrm{NaCl}$ with PVA $\left(C_{\mathrm{PVA}}=100 \mathrm{ppm}\right)$ solutions. Next, the appropriate $\mathrm{pH}$ was adjusted. The suspensions prepared in this way were shaken in a water bath for $24 \mathrm{~h}$ and meanwhile their solution $\mathrm{pH}$ was checked. After this time, these probes were centrifuged and the solid (with or without polymer) was dried. The thermogravimetric analysis of the prepared samples was performed on a derivatograph $Q-1500 \mathrm{D}$ (MOM Hungary) [18]. The TG, DTG and DTA curves were measured in temperature range $20-1000{ }^{\circ} \mathrm{C}$ with a furnace-heating rate of $10{ }^{\circ} \mathrm{C} \min ^{-1}$.

The potentiometric titrations of the alumina in the absence and presence of PVA allowed to determine surface charge density of the solid. The set for these measurements was composed of the following parts: Teflon vessel, burette Dosimat 665 (Methrom), thermostat RE204 (Lauda), pH-meter 71 pH-meter (Beckman) connected with the computer and the printer. The solid surface charge density was calculated with the special program Miar_t. $0.2 \mathrm{~g}$ of the alumina was added into thermostated vessel to $50 \mathrm{~mL}$ of polymer solution in the supporting electrolyte (or only to the supporting electrolyte solution). These volumes of polymer and electrolyte solutions result in their final concentrations $\left(C_{\mathrm{PVA}}=100 \mathrm{ppm} \quad\right.$ and $\left.C_{\mathrm{NaCl}}=1 \times 10^{-2} \mathrm{~mol} \mathrm{dm}^{-3}\right)$. Initial $\mathrm{pH}$ of the solution (3-3.5) was adjusted by the use of $\mathrm{HCl}\left(1 \times 10^{-1} \mathrm{~mol} \mathrm{dm}^{-3}\right)$. The examined systems were titrated with the $\mathrm{NaOH}$ solution $\left(1 \times 10^{-1} \mathrm{~mol} \mathrm{dm}^{-3}\right)$.

The zeta potentials of the alumina particles without and with PVA were measured with the Zetasizer 3000 laser zetameter (Malvern Instruments). The suspension containing $0.02 \mathrm{~g}$ of $\mathrm{Al}_{2} \mathrm{O}_{2}$ in $200 \mathrm{~mL}$ of the supporting electrolyte or polymer solution $\left(C_{\mathrm{PVA}}=100 \mathrm{ppm}\right)$ was prepared. This suspension was ultrasonicated (ultrasonic processor XL, Misonix) and divided into five parts of $40 \mathrm{~mL}$ volume. Next, the appropriate $\mathrm{pH}$ value (ranging from 3 to 10) was adjusted in each sample.

The alumina suspensions for stability measurements were prepared by adding $1 \mathrm{~g}$ of $\mathrm{Al}_{2} \mathrm{O}_{3}$ to $20 \mathrm{~mL}$ of $\mathrm{NaCl}$ or $\mathrm{NaCl}$ with polymer solutions $\left(C_{\mathrm{PVA}}=100 \mathrm{ppm}\right)$. The obtained suspensions were ultrasonicated for $1 \mathrm{~min}$. The formed sediment (about $0.9 \mathrm{~g}$ ) was separated from the stable suspension by decantation. Then, the required $\mathrm{pH}$ of solution was adjusted. The prepared suspension was shaken in a water bath for $30 \mathrm{~min}$ and its $\mathrm{pH}$ was checked. After this time, the changes in the suspension stability were monitored using the UV-VIS Specord M42 spectrophotometer (Carl Zeiss Jena).

\section{Results and discussion}

Figures 1 and 2 represent the adsorption isotherms of PVA 22,000 and PVA 38,000 on the alumina surface for different $\mathrm{pH}$ values of the solution. As can be seen the polyvinyl alcohol adsorption increases with the increasing $\mathrm{pH}$. It is associated with the presence of $2.5 \%$ unhydrolyzed acetate groups $-\mathrm{OCOCH}_{3}$ in the PVA chains (hydrolysis degree 97.5\%). Our previous investigations [19] indicate that these groups show the preferential adsorption on the alumina surface in comparison to that of hydroxyl groups $-\mathrm{OH}$. Possible types of hydrogen bridge interactions between the surface groups $-\mathrm{Al}_{2} \mathrm{O}_{3}$ and the functional groups of PVA are placed in Table 1. Acetate groups contrary to hydroxyl ones dissociate with the rise of $\mathrm{pH}$ and the PVA macromolecules gain negative charge.

On the other hand, $\mathrm{pH}_{\mathrm{pzc}}$ of the alumina surface equals about 8 (Fig. 3). Thus, at $\mathrm{pH} 3$ the electrostatic attractions between the positively charged alumina surface and the slightly dissociated acetate groups take place. The low dissociation degree at low $\mathrm{pH}$ causes a more coiled structure of the adsorbed polymer chains. Such conformation of PVA macromolecules leads probably to blockade of solid active sites and prevents from adsorption of others. For this reason, the lowest adsorption and the thinnest adsorption layer of PVA on the alumina surface (Table 2) were obtained at $\mathrm{pH} 3$.

At pH 6 the PVA acetate groups are practically totally ionized and for this reason its conformation is more developed due to electrostatic repulsion between the acetate groups in the same or different polymer chains. The solid surface is still positively charged and the electrostatic attraction favours adsorption of well developed polymer chains. Such stretched structure of the adsorbed layer does not consume many alumina surface sites and a greater

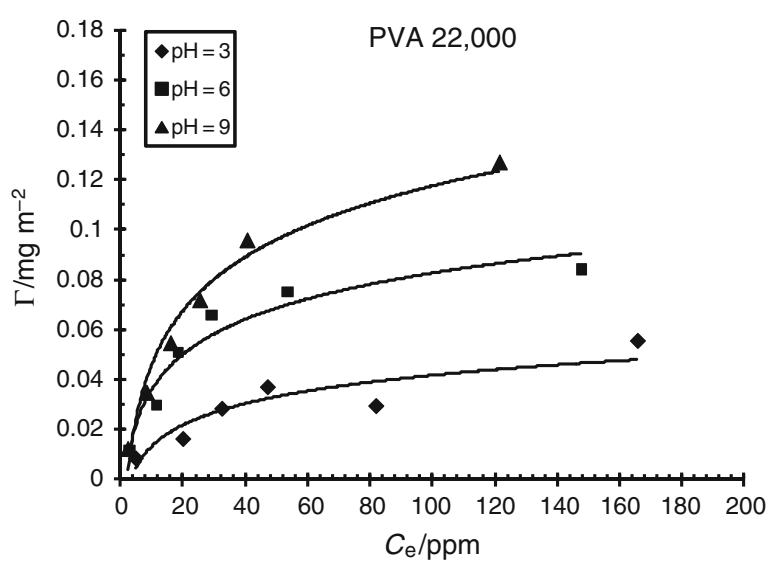

Fig. 1 Adsorption isotherms of PVA 22,000 on the $\mathrm{Al}_{2} \mathrm{O}_{3}$ surface as a function of solution $\mathrm{pH}, C_{\mathrm{NaCl}}=1 \times 10^{-2} \mathrm{~mol} \mathrm{dm}^{-3}$ 


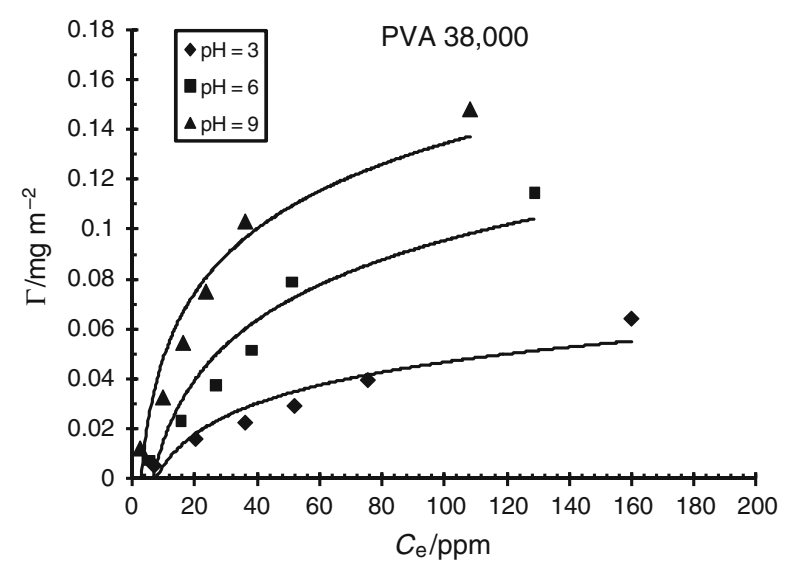

Fig. 2 Adsorption isotherms of PVA 38,000 on the $\mathrm{Al}_{2} \mathrm{O}_{3}$ surface as a function of solution $\mathrm{pH}, C_{\mathrm{NaCl}}=1 \times 10^{-2} \mathrm{~mol} \mathrm{dm}^{-3}$

number of PVA macromolecules can be adsorbed on the unit of surface area. As a result, the adsorbed amount and the adsorption layer thickness are larger.

Despite the fact, that at $\mathrm{pH} 9$ the electrostatic repulsion between the negatively charged polyvinyl alcohol chains and the negatively charged alumina surface occurs, the PVA adsorption and its adsorption layer thickness are the greatest. These repulsive interactions cause a very stretched conformation of the adsorbed macromolecules, which are considerably developed perpendicularly to the solid surface. The packing of adsorption layer is very high in this case, which results in high adsorption level. Moreover, the occurrence of PVA adsorption on the $\mathrm{Al}_{2} \mathrm{O}_{3}$ surface at $\mathrm{pH} 9$ proves that not only electrostatic forces but also hydrogen bridge interactions are responsible for polymer adsorption. Otherwise the adsorption of negatively charged polymer chains on the negatively charged solid surface should not occur.

As can be seen in Table 1, hydrogen bonds can be formed between all types of $\mathrm{Al}_{2} \mathrm{O}_{3}$ surface groups (- $\mathrm{AlOH}$, $-\mathrm{AlO}^{-}$and $-\mathrm{AlOH}_{2}^{+}$) as well as hydroxyl and acetate groups of polymer (both ionized and unionized).

The polyvinyl alcohol adsorption causes changes in the surface and electrokinetic properties of the alumina. The results of potentiometric titrations and zeta potential measurements are depicted in Figs. 3 and 4, respectively.

The analysis of potentiometric titrations curves (Fig. 3) indicates that an insignificant increase of the solid surface charge in the presence of polyvinyl alcohol is observed, especially in the range of high $\mathrm{pH}$ values. Due to the fact that the PVA macromolecules contain acetate groups undergoing dissociation with the increasing $\mathrm{pH}$, their adsorption causes increase of the alumina surface density. Such behaviour is typical of adsorption of anions and not fully hydrolyzed polyvinyl alcohol can be treated as a polyanion.

The $\mathrm{pH}$ increase favours more stretched conformation of adsorbed polymer chains, which are more and more negatively charged and a greater number of acetate groups can be adsorbed on the alumina surface. As a result the increase of the solid surface charge in the presence of PVA with the increasing $\mathrm{pH}$ was obtained.

Moreover, a larger increase of $\mathrm{Al}_{2} \mathrm{O}_{3}$ surface charge in the presence of polyvinyl alcohol with higher molecular weight is observed. It is caused by the fact that a greater number of dissociated acetate groups in longer polymer chains (higher

Table 1 The possible types of hydrogen bridges interactions between $\gamma-\mathrm{Al}_{2} \mathrm{O}_{3}$ surface groups and functional groups of PVA

\begin{tabular}{|c|c|c|}
\hline \multirow{2}{*}{$\begin{array}{l}\text { Type of } \gamma-\mathrm{Al}_{2} \mathrm{O}_{3} \\
\text { surface group }\end{array}$} & \multicolumn{2}{|c|}{ Hydrogen bond } \\
\hline & with acetate groups & with hydroxyl groups \\
\hline $\mathrm{Al}-\mathrm{O}<\mathrm{H}_{\mathrm{H}^{+}}^{\mathrm{H}}$ & & $\mathrm{Al}-\mathrm{O}<\mathrm{H}_{\mathrm{H}^{+}}^{\mathrm{H}-\ldots} \mathrm{O}^{\mathrm{O}}$ \\
\hline $\mathrm{Al}-\mathrm{O}^{-}$ & $\mathrm{Al}_{-} \mathrm{O}_{-} \stackrel{\mathrm{O}}{\mathrm{OI}_{-}}$ & $\mathrm{Al}-\mathrm{O}=-\mathrm{-}-\mathrm{OH}$ \\
\hline \multirow{3}{*}{$\mathrm{Al}-\mathrm{O}-\mathrm{H}$} & $\mathrm{Al}-\mathrm{O}=\mathrm{H} \underset{\mathrm{OH}}{\|_{\mathrm{C}}}$ & \multirow{2}{*}{$\mathrm{Al}-\mathrm{O}^{-\mathrm{H}-\ldots \mathrm{OH}}$} \\
\hline & $\mathrm{Al}-\mathrm{O}-\mathrm{H}^{-} \mathrm{O}=\mathrm{C}-\mathrm{OH}$ & \\
\hline & $\mathrm{Al}-\mathrm{O}^{-} \mathrm{H}-\mathrm{O}_{-}$ & $\mathrm{Al}-\mathrm{O}=\mathrm{H}$ \\
\hline
\end{tabular}




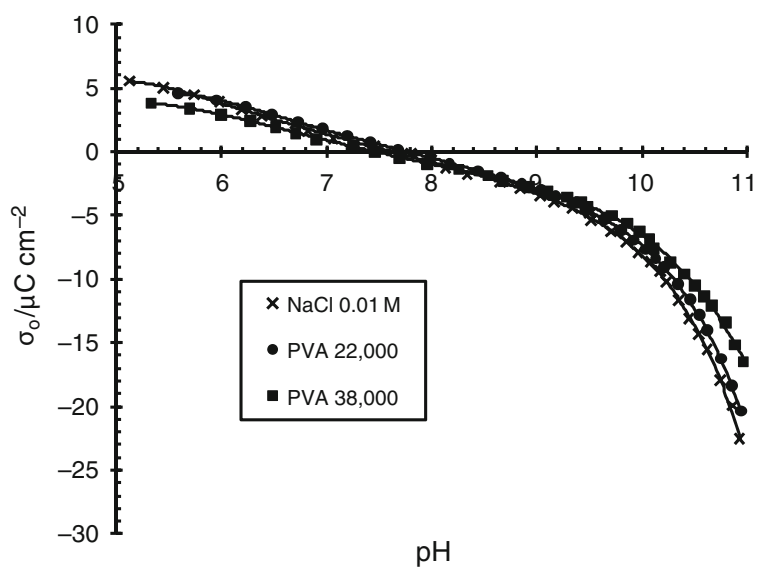

Fig. 3 Surface charge density of $\mathrm{Al}_{2} \mathrm{O}_{3}$ in the presence and absence of PVA as a function of the solution $\mathrm{pH}, C_{\mathrm{NaCl}}=1 \times 10^{-2} \mathrm{~mol} \mathrm{dm}^{-3}$, $C_{\mathrm{PVA}}=100 \mathrm{ppm}$

Table 2 Adsorption layer thicknesses of PVA on the $\mathrm{Al}_{2} \mathrm{O}_{3}$ surface as a function of solution $\mathrm{pH}, C_{\mathrm{NaCl}}=1 \times 10^{-2} \mathrm{~mol} \mathrm{dm}^{-3}$

\begin{tabular}{llll}
\hline System & \multicolumn{3}{l}{ Adsorption layer thickness $\delta / \mathrm{nm}$} \\
\cline { 2 - 4 } & $\mathrm{pH} \mathrm{3}$ & $\mathrm{pH} 6$ & $\mathrm{pH} \mathrm{9}$ \\
\hline PVA 22,000- $\mathrm{Al}_{2} \mathrm{O}_{3}$ & 2.05 & 3.16 & 5.06 \\
PVA 38,000-- $\mathrm{Al}_{2} \mathrm{O}_{3}$ & 2.76 & 4.39 & 6.63 \\
\hline
\end{tabular}

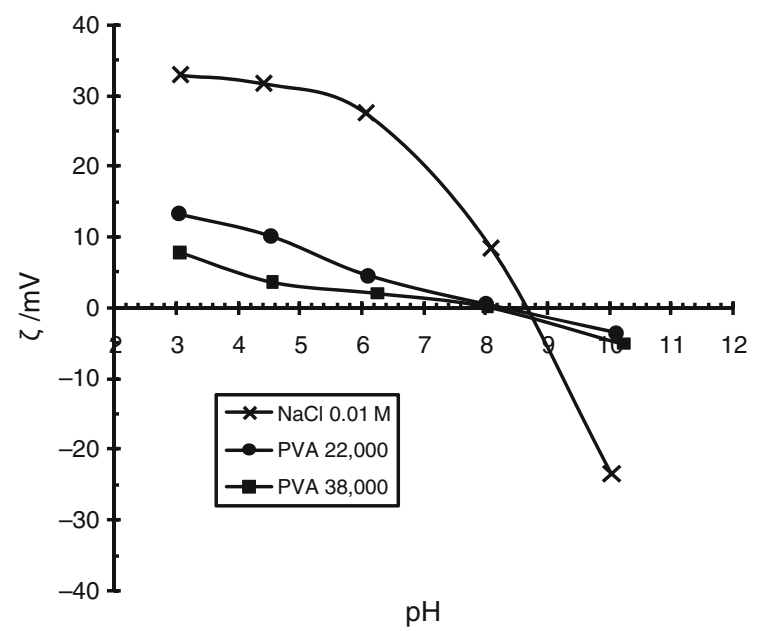

Fig. 4 Zeta potential of $\mathrm{Al}_{2} \mathrm{O}_{3}$ particles in the presence and absence of PVA as a function of the solution $\mathrm{pH}, C_{\mathrm{NaCl}}=1 \times 10^{-2} \mathrm{~mol} \mathrm{dm}^{-3}$, $C_{\mathrm{PVA}}=100 \mathrm{ppm}$

molecular weight) was present. For this reason, the negative charge of polymer chains with higher molecular weight is bigger in comparison to lower molecular weight of PVA. Thus, the adsorption of PVA 38,000 required formation of a greater number of positively charged alumina surface groups and thus the solid surface charge increases.

The polyvinyl alcohol adsorption also influences the electrokinetic properties of the alumina-solution system.
The obtained data from the zeta potential measurements (Fig. 4) suggest that in the $\mathrm{pH}$ range 3-8.5 the zeta potential of $\mathrm{Al}_{2} \mathrm{O}_{3}$ particles in the presence of polyvinyl alcohol is lower than that of the solid in the absence of polymer. At $\mathrm{pH}$ changing from 8.5 to 10 , PVA causes a slight increase of zeta potential of the solid particles. The changes of electrokinetic potential in the presence of macromolecular substance can be caused by three factors: the shift of slipping plane, the blockade of solid active sites by the earlier adsorbed polymer chains and electrolyte ions as well as the presence negatively charged functional groups in macromolecules. The contribution of these effects influences the final value of zeta potential.

In the case of higher molecular weight of PVA, the shift of slipping plane due to polymer adsorption is probably dominating. Longer polymer chains create adsorption layers with great contribution of the polymer segments in tail and loop structures. The increase of the length of these conformational structures leads to larger shift of slipping plane and more pronounced reduction of the zeta potential.

In the case of lower molecular weight of the polymer the blockade of solid active sites by the previously adsorbed polymer chains is the main effect contributing to reduction of the zeta potential of the alumina. It results in a flatter conformation, which usually creates shorter polymer macromolecules on the solid surface.

Additionally, the anionic character of PVA chains can be also responsible for the decrease of the zeta potential of $\mathrm{Al}_{2} \mathrm{O}_{3}$ particles.

For both investigated molecular weights of PVA in the $\mathrm{pH}$ range 8.5-10 polymer adsorption causes the increase of zeta potential of the alumina. It can be explained by displacement of electrolyte ions in the perpendicular direction to the solid surface due to polymer adsorption. Thus, their concentration in the diffuse layer of pwe increases causing the increase of zeta potential.

The conformational changes of polymer chains with the increasing $\mathrm{pH}$ affect the alumina suspension stability in the presence of PVA. The stabilization properties of the investigated systems can be monitored by recording their absorbances as a function of time. The respective curves are presented in Figs. 5, 6 and 7.

The analysis of the obtained dependencies indicates that the alumina suspension was characterized by sufficiently large stability at $\mathrm{pH} 3$ and 6 (Figs. 5, 6). In these cases absorbance changes in the range 1.4-1.6. The PVA addition causes insignificant rise of the solid stability at $\mathrm{pH} 3$ and a pronounced decrease of $\mathrm{Al}_{2} \mathrm{O}_{3}$ stability at $\mathrm{pH} 6$. The most unstable systems were obtained at $\mathrm{pH} 9$ (Fig. 7) and the presence of polymer slightly enhances alumina stability.

The smallest stability of the alumina suspension at $\mathrm{pH} 9$ in comparison to those at $\mathrm{pH} 3$ and 6 , is probably caused by 


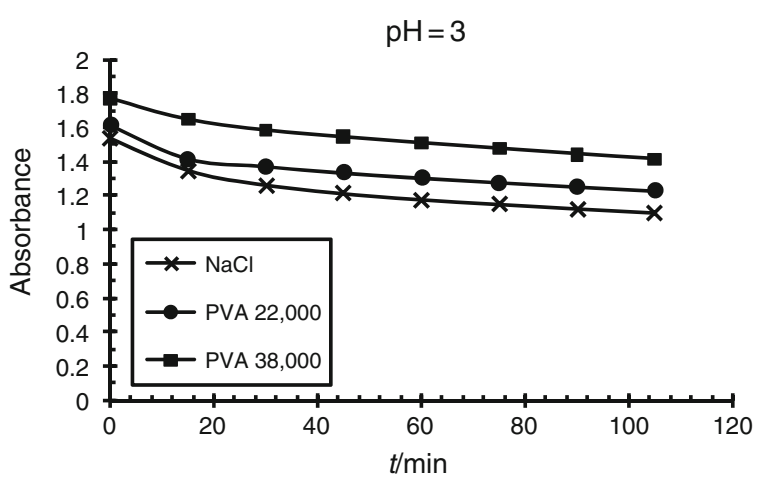

Fig. 5 Absorbances of $\mathrm{Al}_{2} \mathrm{O}_{3}-\mathrm{NaCl}, \mathrm{Al}_{2} \mathrm{O}_{3}-\mathrm{NaCl}-\mathrm{PVA} 22,000$ and $\mathrm{Al}_{2} \mathrm{O}_{3}-\mathrm{NaCl}-\mathrm{PVA} 38,000$ systems as a function of time at $\mathrm{pH} 3$, $C_{\mathrm{NaCl}}=1 \times 10^{-2} \mathrm{~mol} \mathrm{dm}{ }^{-3}, C_{\mathrm{PVA}}=100 \mathrm{ppm}$

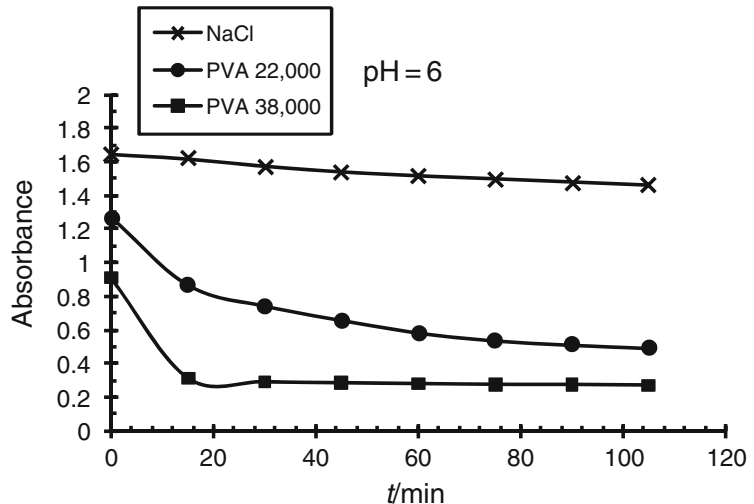

Fig. 6 Absorbances of $\mathrm{Al}_{2} \mathrm{O}_{3}-\mathrm{NaCl}, \mathrm{Al}_{2} \mathrm{O}_{3}-\mathrm{NaCl}-\mathrm{PVA} 22,000$ and $\mathrm{Al}_{2} \mathrm{O}_{3}-\mathrm{NaCl}-\mathrm{PVA} 38,000$ systems as a function of time at $\mathrm{pH} 6$, $C_{\mathrm{NaCl}}=1 \times 10^{-2} \mathrm{~mol} \mathrm{dm}{ }^{-3}, C_{\mathrm{PVA}}=100 \mathrm{ppm}$

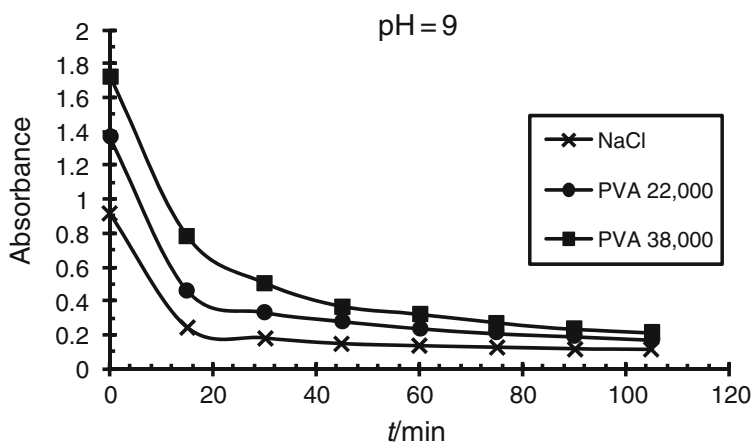

Fig. 7 Absorbances of $\mathrm{Al}_{2} \mathrm{O}_{3}-\mathrm{NaCl}, \mathrm{Al}_{2} \mathrm{O}_{3}-\mathrm{NaCl}-\mathrm{PVA} 22,000$ and $\mathrm{Al}_{2} \mathrm{O}_{3}-\mathrm{NaCl}-\mathrm{PVA} 38,000$ systems as a function of time at $\mathrm{pH} \mathrm{9}$, $C_{\mathrm{NaCl}}=1 \times 10^{-2} \mathrm{~mol} \mathrm{dm}^{-3}, C_{\mathrm{PVA}}=100 \mathrm{ppm}$

the lowest values of surface and diffuse layer charges (Figs. 3, 4). In this situation, the electrostatic repulsion between the solid particles is weak and the system undergoes coagulation.

Adsorption of polyvinyl alcohol at pH 3 is low and its macromolecules have a more coiled structure both in the

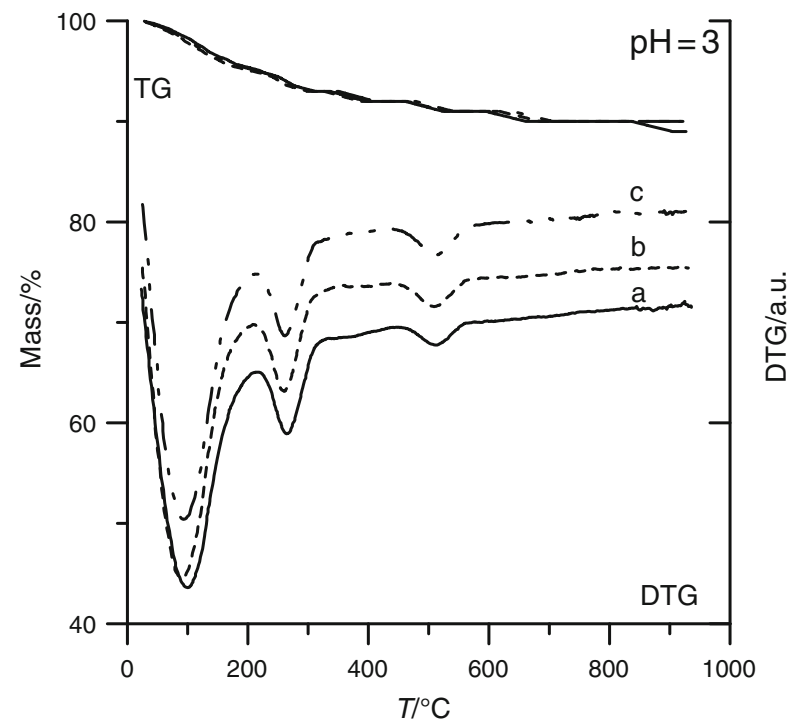

Fig. 8 TG and DTG curves for: (a) $\mathrm{Al}_{2} \mathrm{O}_{3}-\mathrm{NaCl}$, (b) $\mathrm{Al}_{2} \mathrm{O}_{3}-\mathrm{NaCl}-$ PVA 22,000 and (c) $\mathrm{Al}_{2} \mathrm{O}_{3}-\mathrm{NaCl}-\mathrm{PVA} 38,000$ systems at $\mathrm{pH} 3$, $C_{\mathrm{NaCl}}=1 \times 10^{-2} \mathrm{~mol} \mathrm{dm}^{-3}, C_{\mathrm{PVA}}=100 \mathrm{ppm}$

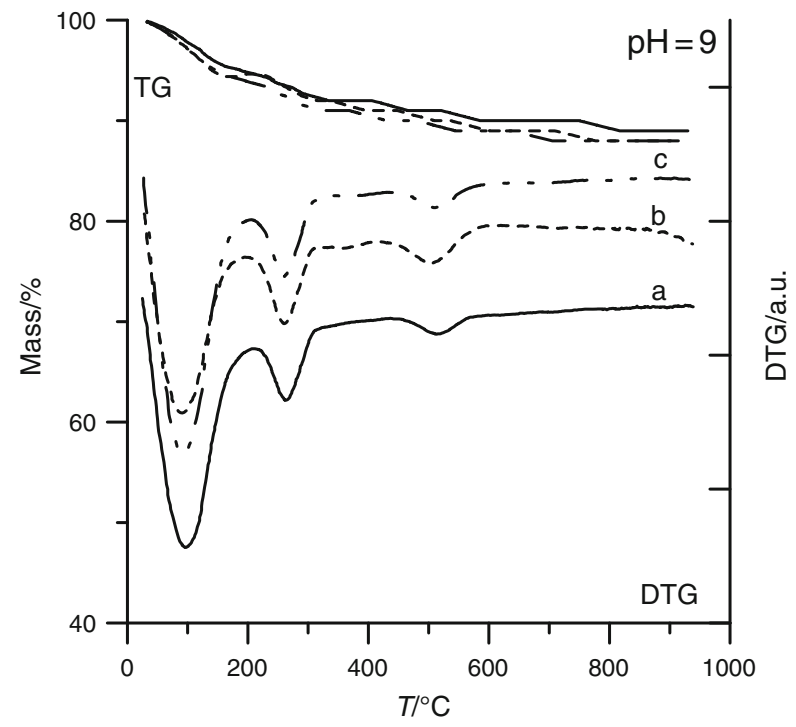

Fig. 9 TG and DTG curves for: (a) $\mathrm{Al}_{2} \mathrm{O}_{3}-\mathrm{NaCl}$, (b) $\mathrm{Al}_{2} \mathrm{O}_{3}-\mathrm{NaCl}-$ PVA 22,000 and (c) $\mathrm{Al}_{2} \mathrm{O}_{3}-\mathrm{NaCl}-\mathrm{PVA} 38,000$ systems at $\mathrm{pH} 9$, $C_{\mathrm{NaCl}}=1 \times 10^{-2} \mathrm{~mol} \mathrm{dm}^{-3}, C_{\mathrm{PVA}}=100 \mathrm{ppm}$

adsorption layer and in bulk solution. The unadsorbed polymer chains are responsible for depletion forces occurrence [20]. For this reason the effect of depletion stabilization may be dominant in the low $\mathrm{pH}$ range.

The obtained decrease of the alumina stability in the presence of PVA at $\mathrm{pH} 6$ is due to formation of polymer bridges between solid particles. The conformation of the adsorbed chains is more stretched, which enables adsorption of a single polymer chain on two or a few alumina particles causing bridging flocculation of the suspension. 
Table 3 Thermal behaviour of $\mathrm{Al}_{2} \mathrm{O}_{3}-\mathrm{NaCl}, \mathrm{Al}_{2} \mathrm{O}_{3}-\mathrm{NaCl}-\mathrm{PVA} 22,000$ and $\mathrm{Al}_{2} \mathrm{O}_{3}-\mathrm{NaCl}-\mathrm{PVA} 38,000$ systems, $C_{\mathrm{NaCl}}=1 \times 10^{-2} \mathrm{~mol}^{\mathrm{dm}}{ }^{-3}$, $C_{\mathrm{PVA}}=100 \mathrm{ppm}$

\begin{tabular}{|c|c|c|c|c|c|c|}
\hline \multirow[t]{2}{*}{ Samples } & \multirow[t]{2}{*}{ DTG peak $/{ }^{\circ} \mathrm{C}$} & \multirow[t]{2}{*}{ Exo $\uparrow / E n d o \downarrow$} & \multicolumn{3}{|c|}{ Mass losses at temperatures $/ \%$} & \multirow[t]{2}{*}{ Total mass losses $/ \%$} \\
\hline & & & $20-200 /{ }^{\circ} \mathrm{C}$ & $200-400 /{ }^{\circ} \mathrm{C}$ & $400-900 /{ }^{\circ} \mathrm{C}$ & \\
\hline $\mathrm{Al}_{2} \mathrm{O}_{3}, \mathrm{pH} 3$ & $94 ; 270 ; 520$ & $\downarrow ; \downarrow ; \downarrow$ & 5 & 2 & 4 & 11 \\
\hline $\mathrm{Al}_{2} \mathrm{O}_{3}-\mathrm{PVA}-22,000, \mathrm{pH} 3$ & $86 ; 266 ; 518$ & $\downarrow ; \downarrow ; \downarrow$ & 5 & 3 & 2 & 10 \\
\hline $\mathrm{Al}_{2} \mathrm{O}_{3}-\mathrm{PVA}-38,000, \mathrm{pH} 3$ & $90 ; 267 ; 519$ & $\downarrow ; \downarrow ; \downarrow$ & 5 & 3 & 2 & 10 \\
\hline $\mathrm{Al}_{2} \mathrm{O}_{3}, \mathrm{pH} 9$ & $93 ; 269 ; 517$ & $\downarrow ; \downarrow ; \downarrow$ & 5 & 3 & 3 & 11 \\
\hline $\mathrm{Al}_{2} \mathrm{O}_{3}-\mathrm{PVA}-22,000, \mathrm{pH} 9$ & $94 ; 254 ; 510$ & $\downarrow ; \downarrow ; \downarrow$ & 6 & 4 & 2 & 12 \\
\hline $\mathrm{Al}_{2} \mathrm{O}_{3}-\mathrm{PVA}-38,000, \mathrm{pH} 9$ & $93 ; 266 ; 518$ & $\downarrow ; \downarrow ; \downarrow$ & 6 & 4 & 2 & 12 \\
\hline PVA-22,000 & $68 ; 306 ; 378 ; 518$ & $\downarrow ; \downarrow ; \uparrow$ & 6 & 64 & 30 & 100 \\
\hline PVA-38,000 & $58 ; 269 ; 404 ; 506$ & $\downarrow ; \downarrow ; \uparrow$ & 4 & 66 & 30 & 100 \\
\hline
\end{tabular}

The effectiveness of flocculation goes up with the increasing molecular weight of polymer. As a result, lengthening of macromolecule favours its adsorption on a greater number of $\mathrm{Al}_{2} \mathrm{O}_{3}$ particles.

An inconsiderable increase in the alumina suspension stability with adsorbed polyvinyl alcohol at $\mathrm{pH} 9$ may be caused by the fact, that at this $\mathrm{pH}$ steric interactions can appear. The adsorbed polymer layer is composed of densely packed, stretched polymer chains (high adsorption, thick adsorption layers). Additionally, the adsorbed PVA macromolecules are fully dissociated and for this reason also electrostatic forces may appear. Thus, the combined electrosteric mechanism of system stabilization is observed.

The thermogravimetric measurements can provide the valuable information about the adsorption mechanism of polyvinyl alcohol on the alumina surface. Figures 8 and 9 represent the TG and DTG curves for the (a) $\mathrm{Al}_{2} \mathrm{O}_{3}-\mathrm{NaCl}$, (b) $\mathrm{Al}_{2} \mathrm{O}_{3}-\mathrm{NaCl}-\mathrm{PVA} 22,000$ and (c) $\mathrm{Al}_{2} \mathrm{O}_{3}-\mathrm{NaCl}-\mathrm{PVA}$ 38,000 systems at $\mathrm{pH} 3$ and 9 . The thermal characteristics of the investigated systems are also placed in Table 3.

There are three regions on the DTG curve of alumina: (1) $20-200{ }^{\circ} \mathrm{C}$ with minimum on the DTG curve at $94^{\circ} \mathrm{C}$-corresponding to the exothermic desorption of hygroscopic and physically adsorbed water, (2) $200-400{ }^{\circ} \mathrm{C}$ with maximum on the DTG curve at $270{ }^{\circ} \mathrm{C}-$ to the endothermic desorption of chemically adsorbed water, and (3) $400-900{ }^{\circ} \mathrm{C}$ with maximum $520{ }^{\circ} \mathrm{C}$ - to the endothermic total dehydroxylation. As can be seen in Figs. 8 and 9 the adsorption of polyvinyl alcohol causes changes in thermal characteristics of the alumina. These changes depend on solution $\mathrm{pH}$ and polymer molecular weight.

Figure 10 represents the TG, DTG and DTA curves for the PVA probes. One can distinguish four successive processes in their course, which agrees with literature data [21]. There are: (1) $58-68{ }^{\circ} \mathrm{C}$-the loss of physically adsorbed water (endothermic), (2) 269-306 ${ }^{\circ} \mathrm{C}$ - the partial dehydration of PVA and polyene formation (endothermic), (3) 404-429 ${ }^{\circ} \mathrm{C}$ - the successive polyene decomposition to macroradicals, acetaldehyde, benzaldehyde, acrolein, cis and trans derivatives as well as polyconjugated aromatic structures (intramolecular cyclization and condensation), (4) $506-518{ }^{\circ} \mathrm{C}$ - the thermo-oxidation of the carbonized residue.

Adsorption of polyvinyl alcohol on the alumina surface changes character of its active sites and influences thermal stability of the solid. Similarly to $\mathrm{Al}_{2} \mathrm{O}_{3}$ without polymer, in the $\mathrm{Al}_{2} \mathrm{O}_{3}-\mathrm{PVA}$ systems three regions on the DTG curves are observed. In the temperature range $20-200{ }^{\circ} \mathrm{C}$, the obtained mass losses correspond to desorption of physically adsorbed water. In the second stage $\left(200-400{ }^{\circ} \mathrm{C}\right)$ the partial dehydroxylation of the alumina surface and polymer (leading to polyene formation) occur [22]. The mass losses increase with the increasing molecular weight of polymer (Table 3 ). The heating process above $400{ }^{\circ} \mathrm{C}$ causes total dehydroxylation of the solid surface and oxidation of organic residues. These effects are smaller due to elimination of water molecules from the alumina surface by adsorbed polymer. Adsorption of macromolecules is surface process due to sieve effects excluding their penetration into adsorbate mesopores.

The obtained changes of thermal characteristic of the alumina with adsorbed PVA are in good agreement with the adsorption data. At $\mathrm{pH} 3$ adsorption of the polymer is not high but structure of adsorbed layer is rather flat (due to the electrostatic attractions between the positively charged alumina surface and the slightly dissociated acetate groups). Such conformation of adsorbed polymer causes that single polymer macromolecule is bonded with the solid surface through a few segment, consuming a few solid active sites and removing water. As a result the total mass loss for $\mathrm{Al}_{2} \mathrm{O}_{3}$-PVA systems is smaller of about $1 \%$ in comparison to $\mathrm{Al}_{2} \mathrm{O}_{3}$ without polymer (Table 3). The opposite situation takes place at $\mathrm{pH}$ 9. In this case the stretched polymer chains occupy a single active sites on the 

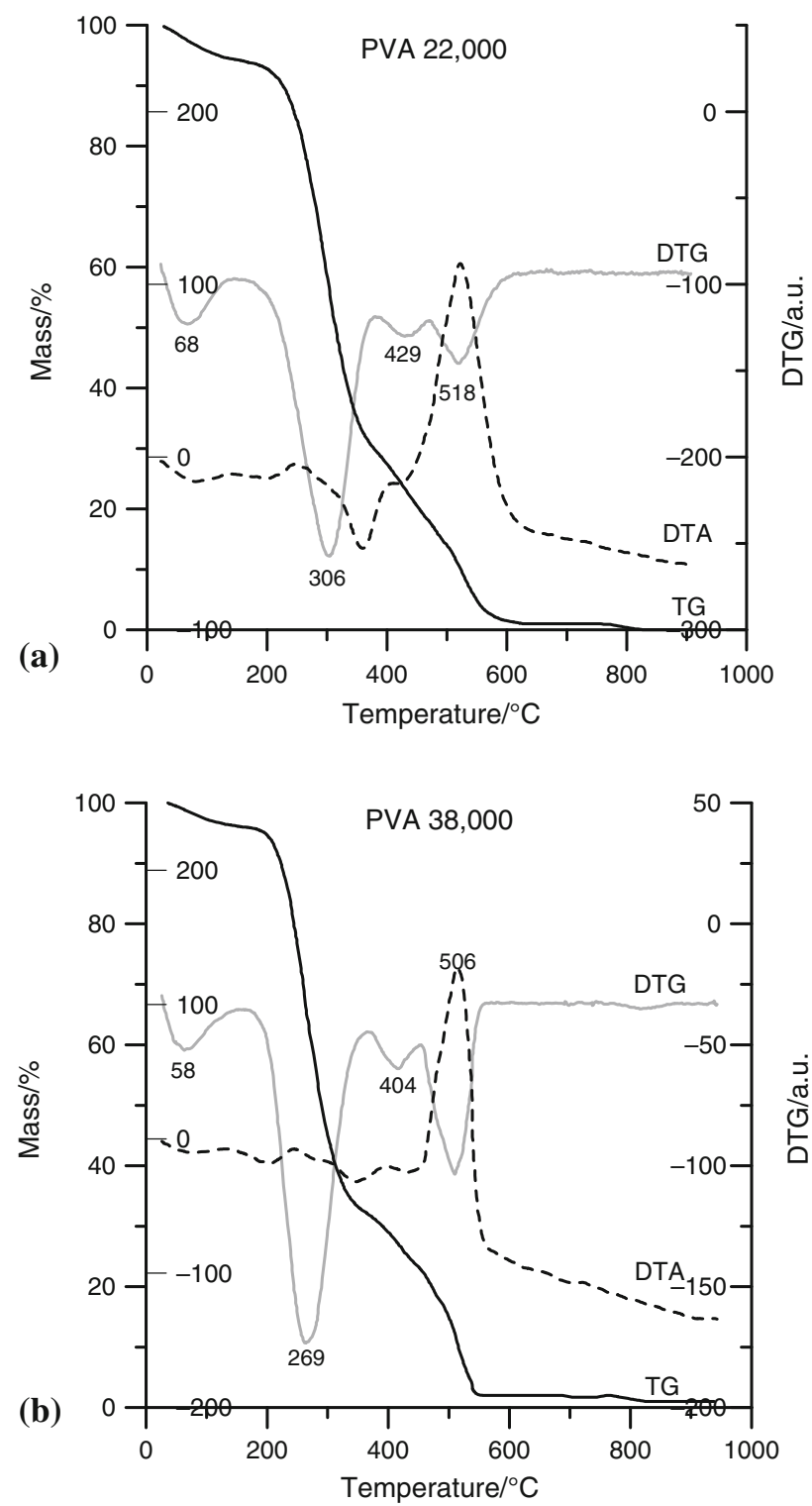

Fig. 10 TG, DTA and DTG curves for a PVA 22,000 and b PVA 38,000

solid surface, which results in the increase of polymer adsorption. It causes the increase of total mass loss of about $2 \%$ in the presence of PVA.

\section{Conclusions}

The effect of solution $\mathrm{pH}$ on the conformation of polyvinyl alcohol chains on the alumina surface was studied. The adsorbed amounts of PVA and its thicknesses of adsorption layers increase with the increasing $\mathrm{pH}$. It results from the presence of $2.5 \%$ unhydrolyzed acetate groups $-\mathrm{OCOCH}_{3}$ in the PVA chains (hydrolysis degree $97.5 \%$ ), which dissociate with the rising $\mathrm{pH}$. These groups show the preferential adsorption on the alumina surface in comparison to hydroxyl ones through hydrogen bridges. The electrostatic repulsion between the dissociated polyvinyl alcohol chains and the negatively charged alumina surface becomes stronger and stronger with the increasing $\mathrm{pH}$. Thus, very stretched conformation of the adsorbed macromolecules at high $\mathrm{pH}$ values produces large adsorption and thick adsorption layer.

The PVA addition causes insignificant rise of the solid stability at $\mathrm{pH} 3$ (depletion stabilization) and a pronounced decrease of $\mathrm{Al}_{2} \mathrm{O}_{3}$ stability at $\mathrm{pH} 6$ (bridging flocculation). The most unstable systems were obtained at $\mathrm{pH} 9$ and the presence of polymer slightly enhances alumina stability (electrosteric stabilization).

Due to the fact that the PVA macromolecules contain acetate groups, their adsorption causes noticeable changes in the alumina surface density and zeta potential of the solid particles.

Polyvinyl alcohol adsorption causes also changes in thermal characteristics of the alumina, especially in the case of higher molecular weight of PVA. It is associated with the modification of solid surface by bonded polymer, whose functional groups compete with water molecules about the alumina active sites, removing them from the interface area.

Acknowledgements This work was supported by MNiSW Grant N204 071 32/1869 in years 2007-2010.

Open Access This article is distributed under the terms of the Creative Commons Attribution Noncommercial License which permits any noncommercial use, distribution, and reproduction in any medium, provided the original author(s) and source are credited.

\section{References}

1. Chibowski S. Effect of functional groups of polyacrylamide and polyacrylic acid on their adsorption onto $\mathrm{TiO}_{2}$ surface. J Colloid Interface Sci. 1990;140:444-9.

2. Vermöhlen K, Lewandowski H, Narres HD, Schwuger MJ. Adsorption of polyelectrolytes onto oxides-the influence of ionic strength, molar mass, and $\mathrm{Ca}^{2+}$ ions. Colloids Surf. 2000; 163:45-53.

3. Steitz R, Leiner V, Siebrecht R, Klitzing R. Influence of the ionic strength on the structure of polyelectrolyte films at the solid/ liquid interface. Colloids Surf. 2000;163:63-70.

4. Wiśniewska M, Chibowski S. Influences of temperature and purity of polyacrylic acid on its adsorption and surface structures at $\mathrm{ZrO}_{2}$-polymer solution interface. Adsorpt Sci Techol. 2005;23: 655-67.

5. Chibowski S, Patkowski J, Opala-Mazur E. Adsorption of commercial, filtrated and fractionated polyethylene oxide onto hematite. Mater Chem Phys. 2005;92:519-25.

6. Ringenbach E, Chauvetau G, Pefferkorn E. Effect of soluble alumina ions on polyelectrolyte-alumina interaction. Kinetics of polymer adsorption and colloid stabilization. Colloids Surf. 1995; 99:161-73. 
7. Pettersson A, Marino G, Pursiheimo A, Rosenholm JB. Electrosteric stabilization of $\mathrm{Al}_{2} \mathrm{O}_{3}, \mathrm{ZrO}_{2}$ and $3 \mathrm{Y}-\mathrm{ZrO}_{2}$ suspensions: effect of dissociation and type of polyelectrolyte. J Colloid Interface Sci. 2000;228:73-81.

8. Leong YK. Depletion interaction in colloidal suspensions: a comparison between theory and experiment. Colloids Surf. 1996; 118:107-14.

9. Das KK, Somasundaran P. A kinetic investigation of the flocculation of alumina with polyacrylic acid. J Colloid Interface Sci. 2004;271:102-9.

10. Zhang J, Huguenard C, Scarnecchia C, Menghetti R, Buffle J. Stabilization and destabilization of hematite suspensions by neutral and anionic polyacrylamide. Colloids Surf. 1999;151:49-63.

11. Liu H, Xiao H. Adsorption of poly(ethylene oxide) with different molecular weights on the surface of silica nanoparticles and the suspension stability. Mater Lett. 2008;62:870-3.

12. Kasprzyk-Hordern B. Chemistry of alumina, reactions in aqueous solution and its application in water treatment. Adv J Colloid Interface Sci. 2004;110:19-48.

13. Porejko S, Fejgin J, Zakrzewski L. Chemistry of macromolecular substances. Warszawa: WNT; 1974. p. 161

14. Zwick MM. Poly(vinyl alcohol)-iodine complexes. J Appl Polym Sci. 1965;9:2393-425.
15. Maslov VI, Kolerko FM. Methods for determination the component of iodopoly(vinyl alcohol) in biological media. Lab Delo. 1972;5:295-7.

16. Garvey MJ, Tadros TF, Vincent B. A comparison of the volume occupied by macromolecules in the adsorbed state and in the bulk solution. J Colloid Interface Sci. 1974;49:57-68.

17. M'Pandou A, Siffert B. Polyethylene glycol adsorption at the $\mathrm{TiO}_{2}-\mathrm{H}_{2} \mathrm{O}$ interface: distortion of ionic structure and shear plane position. Colloids Surf. 1987;24:159-72.

18. Paulik F. Special trends in thermal analysis. New York: Wiley; 1995.

19. Chibowski S, Paszkiewicz M, Krupa M. Investigation of the influence of the polyvinyl alcohol adsorption on the electrical properties of $\mathrm{Al}_{2} \mathrm{O}_{3}$-solution interface, thickness of the adsorption layers of PVA. Powder Technol. 2000;107:251-5.

20. Napper DH. Polymeric stabilization of colloidal dispersions. New York: Academic Press, INC; 1983.

21. Budrugeac P. Kinetics of the complex process of thermo-oxidative degradation of poly(vinyl alcohol). J Therm Anal Calorim. 2008;92:291-6.

22. Sternik D, Staszczuk P, Sobieszek J, Płanda-Czyż M, Wasak S. Influence of albumin adsorption on physico-chemical properties of alumina surfaces. J Therm Anal Calorim. 2006;86:77-83. 